Instructions for authors, subscriptions and further details:

http://generos.hipatiapress.com

\title{
Maternidades Confrontadas. EI Uso Político del Lenguaje en los Discursos sobre la Maternidad Subrogada.
}

Pau Francesch Sabaté ${ }^{1}$

1) Universitat de Barcelona. España

Date of publication: June $25^{\text {th }}, 2017$

Edition period: June - October 2017

To cite this article: Francesch Sabaté, P. (2017). Maternidades Confrontadas. El Uso Político del Lenguaje en los Discursos sobre la Maternidad Subrogada. Multidisciplinary Journal of Gender Studies, 6(2), 1361-1384. doi: 10.4471/generos.2017.2614

To link this article: http://dx.doi.org/10.4471/generos.2017.2614

\section{PLEASE SCROLL DOWN FOR ARTICLE}

The terms and conditions of use are related to the Open Journal System and to Creative Commons Attribution License (CC-BY). 
GÉNEROS-Multidisciplinary Journal of Gender Studies Vol. 6 No. 2 June 2017 pp. 1361-1384

\section{Confronted Motherhoods. The Political Use of Language in Surrogate Motherhood Discourses}

Pau Francesch Sabaté

Universitat de Barcelona

\section{Abs tract}

The analysis of surrogate motherhood and regulative solutions development require terminological and semantic basis on which to establish critics to the injustices that wrap the management of this practice. The lack of definition that covers the surrogacy agreement enables the existence of ambiguities around the pregnant woman's right of filiation and her maternal status. Moreover, the uncertainty about the political potential of surrogate motherhood hinders perception of the problems arising from its socialization, as well as the factors that delimitate its emancipatory scope. With the intention to delineate another regulation proposal this article aims to discuss the suitability of the transformation of subrogation into a new social right.

Keywor ds: surrogate motherhood, discourse, genetics, will, surrogacy agreemen t 
GÉNEROS-Multidisciplinary Journal of Gender Studies Vol. 6 No. 2 June 2017 pp. 1361-1384

\section{Maternidades Confrontadas. El Uso Político del Lenguaje en los Discursos sobre la Maternidad Subrogada}

Pau Francesch Sabaté

Universitat de Barcelona

\section{Resumen}

El análisis de la maternidad subrogada y el desarrollo de soluciones regulativas requieren fundamentos terminológicos y semánticos sobre los cuales instalar las críticas a las injusticias que circundan la gestión de dicha práctica. La indefinición que encubre el contrato de subrogación posibilita la existencia de ambigüedades entorno al derecho de filiación de la mujer gestante y su estatus materno. Por otra parte, el desconcierto acerca del potencial político de la maternidad subrogada dificulta la percepción de los problemas derivados de su socialización, así como los factores que delimitan su abasto emancipador. Con la voluntad de delinear otra propuesta de regulación este artículo pretende discutir la idoneidad de la conversión de la subrogación en un nuevo derecho social.

Palalbras clave: maternidad subrogada, discurso, genética, voluntad, contrato de subrogación 
$\mathbf{N}$ o basta con tener razón, de poco sirve la verdad si la situación estratégica desde la cual se enuncia limita el alcance semántico de nuestras palabras. Todo discurso que aspire a la hegemonía debe cuidar su instalación en la ontología. El valor moral y la coherencia interna de un enunciado son genuinamente seductores en la medida en que conquistan las palabras que el filósofo perspicaz anticipa en boca de sus detractores.

No hace mucho leí un sugerente y crítico artículo sobre la necesidad de abordar la «gestación por sustitución» desde una perspectiva feminista. $\mathrm{Su}$ autor concluía que solo una estricta y observante regulación garantista podía evitar «la instrumentalización de las mujeres y su cuerpo» (Salazar, 2016). La publicación había alentado diversos comentarios. Un detractor atacaba enérgicamente la tesis prescindiendo discutirla abiertamente; cuestionaba el sentido otorgado a las palabras mediante las cuales las conclusiones eran explicadas.

La maternidad subrogada es la técnica consistente en la inseminación artificial de un embrión fecundado in vitro a partir de los óvulos de una mujer distinta a la que lo gestará. La generalización de este fenómeno modifica múltiples patrones tradicionales de sociabilidad relativos a las condiciones y las características de los progenitores como la orientación sexual, la edad y la relación entre estos. Las prácticas heterosexuales, la concepción y la gestación se han escindido en tres esferas paralelas de actividad. La factibilidad de la disociación entre la maternidad biológica y la maternidad gestante abre las puertas a la contractualización de la figura de la madre subrogada, hecho que conlleva «la elevación a público» de la actividad reproductiva, su reconocimiento legal — con la consiguiente neutralización de los conflictos latentes - mediante la formalidad del contrato.

En el presente artículo abordaré algunas de las confusiones y falacias semánticas y perceptivas que dificultan la comunicación y discusión de las visiones críticas con la maternidad subrogada (de ahora en adelante MS). ¿Ha sido nunca la biología femenina una fuente de opresión? ¿Qué valor tiene la gestación en tanto que criterio de filiación al lado de una concepción intencional de la maternidad? ¿Resulta consistente la defensa de la separación entre el cuerpo y la persona cuando se defiende la libertad de 


\section{Francesch Sabaté-Maternidades Confrontadas}

comercio con el propio cuerpo? ¿Son los genes un criterio de filiación liberador por oposición a la gestación? ¿Qué condicionamiento juega el contrato de MS en la relación entre la madre gestante y la parte solicitante? ¿Garantiza neutralmente los derechos de las partes involucradas? ¿O fija y asegura una relación mercantil? ¿Se vende un servicio de gestación o la potestad sobre un hijo? ¿Qué rol desempeñan los hombres en los contratos de subrogación? ¿Hablar de una regulación de la MS conlleva inevitablemente el reconocimiento de nuevos derechos? ¿O se trata de una realidad que hasta cierto punto se encuentra más allá del lenguaje y el alcance del Derecho y el Estado?

La frecuente carencia de términos concisos en los debates políticos entorno al uso de nuevas tecnologías posibilita la creación temporal de posiciones dicotómicas a partir de la confrontación estática de argumentos basados en diferentes usos del lenguaje. El resultado de este impasse semántico es la congelación de las propuestas críticas - a menudo acalladas - en beneficio de la progresiva institución del universo semántico de las comunidades tecno-científicas que impulsan las tecnologías. En tanto que responsables de las innovaciones e investidas de autoridad científica, estas corporaciones disponen de ventaja en la catalogación de las realidades emergentes.

La operación de significación de nuevas relaciones sociales nunca fue una acción apolítica, únicamente orientada por criterios funcionales o técnicos. La entrada de las relaciones mercantiles en los diversos ámbitos de la vida deviene espoleada por un movimiento generalizado de transformación de las relaciones sociales, los ordenamientos jurídicos y la economía de los bienes simbólicos.

De acuerdo con la visión de Raweyn Connell (2011), el neoliberalismo debe ser comprendido en base a su capacidad ontoformativa. Es decir, el potencial de este movimiento para crear realidades generalizadamente interconectadas a partir de la combinación de un programa macroeconómico que implica la modificación del ethos social ${ }^{1}$ de las distintas comunidades en las cuales es aplicado. Modifica su visión del mundo, así como la comprensión de sí mismas (Connell, 2011, p.43).

En este sentido la mediación tecnológica en la reproducción humana ha transformado las múltiples relaciones e instituciones sociales que estructuran los sistemas de parentesco y la significación social de la 
maternidad. Encabezando el abanico de técnicas procreativas desarrolladas durante las tres últimas décadas la MS ha devenido una práctica paradigmática por lo que concierne al carácter problemático de la instrumentalización de la biología humana con fines reproductivos.

\section{La biología no oprime a nadie}

Un confuso debate sobre el potencial emancipador de la MS tiene lugar allí donde esta práctica deviene una realidad más o menos manifiesta. A menudo la retórica de la libertad de uso del propio cuerpo ha enturbiado la discusión a partir de su confusión con una falaz problematización de la biología femenina.

De acuerdo con determinados posicionamientos liberales la tecnología de subrogación hace posible la liberación respecto las constricciones carnales que la necesidad de gestar hijos propios impone. La gestación en tanto que capacidad intrínsecamente femenina no sería más un obstáculo para la autonomía de la mujer. La mediación tecnológica permite la toma de decisiones sobre las propias capacidades reproductivas. Dicho razonamiento conlleva la afirmación implícita que antes de la socialización de esta técnica el aparato reproductor era un factor subyugante más para la mujer.

El infructuoso debate aquí planteado se tambalea ante la aseveración que la emancipación es una condición social y como tal no puede ser el resultado de diferencias biológicas, sino de las instituciones sociales que articulamos a su alrededor y los discursos mediante los cuales las explicamos.

El potencial emancipador de la MS tampoco puede ser reconocido en la posibilidad de «alinear», «alquilar», «prestar servicios» o «trabajar-con» el propio útero. Dichos usos constrictores son algunos de los resultados de las nuevas opciones respecto el cuerpo. No obstante, la libertad individual respecto al nuevo abanico de posibilidades no deviene emancipadora por sí misma. La sociedad en la cual es ejercida restringe e instrumentaliza la subrogación de acuerdo con los criterios del mercado y el patriarcado. Solo podemos atribuir un valor emancipador a la MS en la medida en que los usos que las mujeres hacen de ésta superan genuinamente la autoridad masculina y la necesidad económica. 


\section{Francesch Sabaté-Maternidades Confrontadas}

Resulta innegable el valor emancipador de la maternidad subrogada sin ánimo de lucro por lo que respecta a la posibilidad de su ejercicio por parte de mujeres solteras, estériles y deseosas de ser madres. Este consiste en el establecimiento autónomo de acuerdos y la colaboración entre mujeres en los ámbitos de la reproducción y los cuidados sin la presencia de una figura paternal. La significación política de la MS en relación a la dimensión de la diferencia biológica depende de la regulación jurídica que se le atribuya, así como del uso que la mujer pueda darle. El uso emancipador de la procreación médicamente asistida iría orientado a la superación de los vínculos constitutivos que atan la mujer al padre de la descendencia.

La dicotomía naturaleza-cultura puede operar como un dispositivo jurídico patriarcal en los dilemas asociados a la contractualización de la maternidad subrogada. Su relevancia deviene manifiesta cuando esta construcción es usada como un pseudo-argumento científico. Se pretende discernir si la voluntad de la madre subrogada es en todo momento libre o contrariamente, queda invalidada por la biología femenina y los cambios hormonales asociados al embarazo.

La ley española prohíbe que las mujeres heterosexuales, solteras y estériles acuerden transmitir su material genético a otra mujer para que lo geste. La relación de subrogación entre mujeres constituye un paso emancipador alcanzable. Exenta de ánimo de lucro y de constricciones contractuales limitadoras de la autonomía de la madre gestante iría en consonancia con la superación de la pareja heterosexual procreadora y la legítima elección de un modelo de familia alternativo.

\section{¿Maternidad o ges tación?}

Distintas voces y organizaciones -entre las cuales encontramos el colectivo Son Nuestros Hijos (SNH) ${ }^{2}$ - se muestran críticas con el uso del término «maternidad subrogada» en base a la idea que aquello substituido o subrogado es la gestación, no la maternidad. Ésta última es explicada como «un proceso físico, psicológico, biológico y anímico que no termina nunca», mientras que «la gestación es un proceso biológico que dura nueve meses» (Fuentes, 2016).

La sustitución del término «maternidad» por «gestación» puede derivar una despolitización y desmoralización de la actividad, la técnica y las relaciones que circundan la MS. Reducir la subrogación a la venda o 
donación de mera «capacidad de gestación» esconde que la gestación es una parte de la maternidad en tanto que proceso expresamente parcelado.

Los posibles criterios de filiación son tres, dos biológicos - el parto y la información genética- y uno intencional, la voluntad procreacional. La maternidad en tanto que proceso multidimensional no debería reducirse a su reconocimiento jurídico o a las actividades de crianza posteriores al parto, si esto perjudica el estatus y los derechos de la madre gestante. De la misma forma que se reconoce que la persona vendedora de su tiempo de trabajo no aliena únicamente energía física, ya que se vende a sí misma, su tiempo, órganos, sistemas, «emociones», «habilidades» y recuerdos; la mujer que alquila su útero vende la «singular capacidad fisiológica, emocional y creativa de su cuerpo, es decir, se sí misma en tanto que mujer» (Pitch, 2003, p.46).

Dicha tentativa de giro terminológico constituye una operación de vaciado de sentido. Esta maniobra conceptual hace posible la desatención de los problemas éticos asociados a la resignificación de un fenómeno fundamental como la maternidad. El reconocimiento jurídico de la madre gestante como parte legítima en la atribución de la filiación deviene la consecuencia primera de la categorización del embarazo como un fragmento de la maternidad. El uso de toda terminología fragmentaria relativa al «alquiler del útero» contribuye a la situación de la madre subrogada en una posición de inferioridad dentro de la relación de poder establecida entre ésta y la parte que solicita sus servicios. La definición servicial, impersonal y descarnada de la maternidad comporta el ocultamiento del contexto personal y los potenciales daños físicos y psíquicos en la mujer contratada.

El vaciado de toda connotación maternal aplicado a la actividad de gestación permite la legitimación de la venta del estatus de madre cuando la subrogación se lleva a cabo con afán de lucro. Si la tutela no es reconocida a la mujer gestante ésta no vende formalmente su estatus de madre. Consecuentemente, si la actividad de gestación deviniera remunerada, la compra afectaría a un "neutral servicio" realizado con el útero, un órgano equiparable a cualquier parte del cuerpo empleada para trabajar. La maternidad - realmente fundamentada en relaciones de $d o n^{3}-$ no se descubriría determinada por relaciones mercantiles. 
Tabla 1.

Implicaciones de la disociación maternidad-gestación.

\begin{tabular}{|c|c|c|}
\hline VALOR DEL PARTO & FILIACIÓN & ESTATUS DE MADRE \\
\hline siempre implica maternidad & SI & se vende en la \\
subrogación \\
\hline no es condición suficiente de \\
la maternidad
\end{tabular}

Fuente: elaboración propia

Por otra parte, podemos emplear la distinción entre la maternidad subrogada y la maternidad subrogada no social para precisar aquellos casos en que la mujer gestante también es reconocida como madre social y jurídica. Sin embargo, esta posibilidad no excluye que la gestación sin posterior filiación sea una parte relevante de la maternidad entendida como un proceso polietápico.

\section{La jerga de la alienación cuerpo-persona}

La tecnología permite escindir las personas que toman la decisión de ser madres respecto de los cuerpos que producirán los óvulos y los gestaran. Paralelamente, la jerga de la separación cuerpo-persona explota políticamente la idea que gracias a las técnicas de reproducción asistida por primera vez deviene posible hacer un uso plenamente «racional» $\mathrm{y}$ voluntario de las capacidades reproductivas. El "triunfo de la voluntad" lleva a un enaltecimiento del consumo y la venta de la MS sobre la base de la «intención» ${ }^{4}$ (Iacub, 2005, p.148-157).

Lo discutible pasa por la legitimación de la escisión cuerpo-persona, no obstante -más allá del formalismo liberal - en este caso se trata de una separación material, o "carnal” si se prefiere. En palabras de Marcela Iacub: «por primera vez, sin duda, en la historia occidental, la maternidad devenía sin "fraude" alguno tan poco carnal como podía serlo la paternidad» ${ }^{5}$ (Iacub, 2005, p. 156). 
La ideología liberal presente tras esta concepción del cuerpo tiende a la total abstracción del sujeto que cree liberado. Dicha condición de ausencia del cuerpo respalda la antropología jurídica neoliberal que legitima la compra-venta de los órganos femeninos bajo el velo de la liberación. El sujeto abstracto, descarnado - y por tanto asexuado - oculta el contexto socioeconómico que condiciona la madre subrogada a vender el uso de su útero. Al mismo tiempo, promueve las relaciones patriarcales derivadas de la participación de hombres en el contrato de subrogación.

La corporeidad neoliberal oscurece la distinción entre los derechos económicos asociados a la libertad de comercio y los Derechos Fundamentales ligados a la disposición del cuerpo. La posibilidad de abrir el propio cuerpo al mercado deviene la condición de una ciudadanía plena, basada en el reconocimiento de la íntegra capacidad de toma de decisiones. De acuerdo con esta lógica, la mercantilización de nuevos ámbitos de la vida femenina mediante la figura del contrato supondría un paso adelante hacia la emancipación.

La libertad formal para atarse en contratos puede transformar en "trabajo no remunerado" toda aquella actividad no regida por una relación salarial. El nuevo contractualismo abandona el cuerpo, aleja el Derecho de la vida y esconde cuestiones cruciales como el impacto psíquico del ejercicio de la actividad de gestación y la vinculación entre el sexo y la gestación ${ }^{6}$.

Como afirma Tamar Pitch (2003, p.39), el neocontractualismo sitúa la persona real bajo «condición de ausencia»:

La autonomía es tanto el presupuesto como la consecuencia del contrato: sólo los sujetos autónomos pueden contratar válidamente; regular a través de un contrato un cierto ámbito produce y construye sujetos autónomos. En este contexto, autonomía significa capacidad de elección racional, es decir, de elección basada sobre un cálculo de costes y beneficios. Significa, en otras palabras, bien una condición de ausencia (o de ponerlos entre paréntesis) de vínculos precedentes a la elección, bien la capacidad de abstraerse, de separarse, de ponerlos al menos en la cuenta de los costes.

Respondiendo la tesis de Iacub (2005) podemos afirmar que la maternidad no deviene «tan poco carnal como podía serlo la paternidad» gracias a una producción y crianza de los hijos automatizada o a coste de 


\section{Francesch Sabaté-Maternidades Confrontadas}

trabajo cero, sino vía externalización del trabajo y la sustitución de la corporeidad de la mare genética mediante el trabajo de otras madres subrogadas.

\section{El papel del contrato y la mercantilización de la actividad reproductiva}

La MS con afán de lucro ha sido acusada de introducir relaciones mercantiles en la esfera de la reproducción humana y el cuerpo femenino. Son ya conocidos los estudios sobre las organizaciones de trata de personas vinculadas a los contratos de MS entre agencias y mujeres solicitantes de países desarrollados y mujeres del tercer mundo ${ }^{7}$. Generalmente se admite el carácter éticamente problemático de condicionar el embarazo y la cesión de un hijo a la percepción de una retribución económica lucrativa. Aunque la "compensación" económica supere los 50 o 100 mil dólares y las condiciones sanitarias de la madre gestante estén aseguradas, la venta de la gestación y de la potestad sobre el hijo puede ser el resultado de presiones asociadas a necesidades económicas. Sin embargo, los discursos críticos con la mercantilización del cuerpo femenino y la reproducción humana tienen una repercusión y aceptación bastante limitadas, especialmente en determinados círculos feministas y de izquierda.

Son muy llamativas las reacciones que enaltecen el ejercicio de la MS como una profesión emergente y emancipadora:

Jamás has hablado con una gestante americana, mujeres hechas de una pasta especial que no sólo no se consideran "cosificadas" o "una mercancía" sino que presumen de gestar el hijo de otra u otras personas en sus perfiles de facebook, en blogs, en infinidad de fotos en instagram ${ }^{8}$. (Salazar, 2016)

Más allá de las tentativas de defensa del valor moral de gestar para ayudar a personas necesitadas abundan también inespecíficas justificaciones de su remuneración.

La mercantilización de la actividad reproductiva es el proceso mediante el cual las relaciones sociales necesarias para la satisfacción del deseo de procreación de un individuo o pareja pasan a tener lugar en un contexto mercantil. La puesta en común de los recursos y las voluntades destinadas a 
la concepción del hijo se rige por un nexo económico que vincula las personas implicadas.

La discusión en torno al valor moral de gestar y concebir con ánimo de lucro pasa por determinar el objeto de la remuneración o qué deviene vendido y quién se enriquece. El objeto de la remuneración se atribuye contractualmente al «servicio» o al «trabajo» de gestación. Sin embargo, como ya hemos visto, la existencia de una compraventa de la potestad sobre el hijo depende del reconocimiento formal de la maternidad a la mujer gestante:

No se compra ningún bebé puesto que ese bebé procede de un embrión que no existiría si no lo hubieran creado los padres de intención, que han recurrido a una clínica para realizar una fecundación in vitro con ayuda o no de donantes de gametos ${ }^{9}$. (Salazar, 2016)

Si la maternidad es legalmente negada a la madre gestante desde el inicio de la relación de subrogación la cuestión se enturbia, permitiendo el ocultamiento de la potestad. Los padres solicitantes no contratan la madre subrogada con la exclusiva finalidad que esta devenga embarazada. El deseo que motiva la relación mercantil es la obtención de un hijo y por consiguiente, la transacción persigue y finaliza con la entrega y adquisición de la descendencia engendrada por la madre gestante. En otras palabras, las propiedades circulantes son dinero y la potestad sobre personas neonatas.

Por lo que respecta a la defensa de la profesionalización de la MS, esta ha sido defendida como una ayuda en la desigual sobrecarga femenina de trabajo reproductivo y de cuidados en las familias. $\mathrm{Su}$ aplicación a los problemas de género asociados a las tareas reproductivas no se encuentra exenta de problemáticas. La profesionalización de la maternidad ha sido propuesta como un contrapeso ante la salida femenina de la exclusividad del trabajo doméstico. Se pretende reconciliar la identidad femenina con la maternidad mediante «la asignación de responsabilidad moral a las madres para con la provisión a sus hijos de "el mejor inicio en la vida" (...) para sobresalir en un mundo competitivo» (Connell, 2011, p.53).

Connell ha acuñado el término desencarnación de la maternidad (disembodying of motherhood) para explicar la creciente disminución de la para explicar la creciente disminución de la implicación del cuerpo materno 


\section{Francesch Sabaté-Maternidades Confrontadas}

a las tareas de cuidados y reproductivas. Su análisis constata que e ste fenómeno no desplaza la centralidad de la madre en el cumplimiento del trabajo reproductivo en su división de género ${ }^{10}$. La reconfiguración neoliberal de las instituciones que circundan la familia - manifiesta en el mercado de servicios reproductivos y la privatización de la escuela, así como de toda asistencia social - ha llevado los progenitores a concebir el hijo como una inversión a gestionar en el marco del cuadro ético liberal de la competitividad en "igualdad de oportunidades".

Esta visión competitiva de la planificación familiar pesa ya sobre la mujer antes de la gestación de la descendencia. Connell sitúa el inicio de la planificación en el nacimiento. No obstante, las familias pueden encontrar el primer embate "managerial" a resolver en la realización de un diagnóstico genético preimplantacional ${ }^{11}$ (DGP) con tal de conocer las características del futuro hijo. Otro indicio de planificación prenatal puede ser identificado en la posibilidad de contratar la MS. De esta forma la madre genética no verá peligrar su posición en el mercado laboral y la familia mantendrá su poder adquisitivo.

\section{La gené tica legitima la voluntad de apropiación}

Anteriormente hemos discutido la idea según la cual la separación técnica de los dos principios carnales de la maternidad - los genes y el embarazohace posible que la madre y el hijo estén «atados por una relación puramente moral: la voluntad» (Iacub, 2005, p.156), contribuyendo por tanto a la emancipación de la mujer en la actividad reproductiva.

Haciendo uso de la jerga de la «genética y la voluntad», en base a la idea que el neonato no adquiere los genes de la madre subrogada, se pretende justificar la ausencia de vinculación materno-filial entre la madre gestante y el hijo.

La consciencia entorno al poder normativo de la genética desvela el carácter dudoso de los discursos que celebran la liberación respecto al parto en tanto que criterio de atribución de la filiación y orientan las esperanzas progresistas hacia la superación técnica de la biología femenina. En el ensayo L'impero del ventre, Iacub (2005) pone en tela de juicio que el suceso biológico del parto deba ser el exclusivo criterio para la creación de vínculos jurídicos de filiación. Dicha tesis se basa en la anteposición del parto a la voluntad en tanto que criterio de filiación. De acuerdo con la 
autora, el antiguo código civil napoleónico del 1804 atribuía indistintamente la capacidad de adscripción de los hijos tanto al parto como a la voluntad, siendo ésta una legislación que empoderaba en mayor medida la mujer frente al patriarcado estatal ${ }^{12}$.

La autora traza un período de inflexión que abarca desde el siglo XIX hasta los años treinta del siglo XX durante el cual la imposición de la regla - o dispositivo - de «la verdad del parto» como criterio de maternidad se fortaleció y tanto las madres subrogadas como los partos anónimos pasaron a ser objeto de persecución. Su crítica puede ser resumida en la idea que la subversión del antiguo modelo «napoleónico» de filiación - reconocedor de la voluntad de los progenitores - ha supuesto un paso atrás en el proceso de emancipación de la mujer. De acuerdo con Iacub (2005) la defensa conservadora del modelo basado en la verdad del parto pretende la restricción de todo uso emancipador de la MS. Desde su punto de vista, parece que aquello urgentemente necesario sea la legalización de los contratos de subrogación, especialmente los de tipo mercantilremunerado ${ }^{13}$.

La discusión de los enfoques como el que acabamos de describir requiere la clarificación de inconsistencias como «la liberación respecto el parto» y su anteposición a la voluntad. Es preciso estimar el poder de la genética en cuanto código o factor con fuerza normativa. También es necesario discutir la identificación directa e irreflexiva de la voluntad de procrear con una libertad política y colectiva.

El ascenso de la genética como un criterio de filiación libre en la MS es un nuevo constructo social que legitima la voluntad de la parte solicitante en tanto que autoridad para ser reconocida progenitora. Lejos de representar una liberación respecto la biología, la «voluntad procreacional» implica la institución de la rígida sanción biogenética en las relaciones entre la familia y el Estado. En este caso la voluntad encubre el deseo de potestad posesiva o poder-sobre el hijo resultante. La apropiación se lleva a cabo en el contexto de relaciones mercantiles -susceptibles de devenir jerárquicas - de compra de las capacidades y la descendencia de otras.

Por otro lado, el parto en tanto que criterio se basa en una modalidad positiva del poder, no necesitada de sumisión ajena para desarrollarse. Se trata de la capacidad o potencia de poder-hacer un hijo a partir del propio cuerpo y el deseo. 


\section{Francesch Sabaté-Maternidades Confrontadas}

El concepto de «voluntad responsable» que sostiene el contrato liberal se apoya en una noción económica e inmutable del individuo racional. Autorizar de forma prioritaria la voluntad procreacional de la parte contratante en caso de litigio por la maternidad implica a la vez la subyugante «presunción de irracionalidad uterina de la mujer gestante» (Pitch, 2003, p.50). Éste es el resultado de la fijación de las capacidades reproductivas de la mujer a la lógica contractual. Una regla completamente hostil al reconocimiento de una irracionalidad mutable en el tiempo ${ }^{14}$ en tanto que atada a las condiciones personales y corporales. Factores psicológicos condicionados a la fisiología femenina como el embarazo y la conciencia de llevar otra vida en el interior son ajenos a la lógica de instituciones axiomáticas como el mercado y la norma burocrática.

\section{La presencia masculina en las relaciones de subrogación}

La configuración de una perspectiva radicalmente feminista permite combatir y abordar de forma distinta los casos en los cuales el Derecho y las resoluciones judiciales anteponen el valor del contrato a la autonomía femenina y al derecho a la inviolabilidad sobre el propio cuerpo. La falta de reconocimiento de la centralidad del cuerpo femenino repercute en una falaz pretensión de igualdad y neutralidad en la legislación en materia de MS.

Pitch ejemplifica esta necesidad con el paradigmático caso de Baby M; una mujer que una vez comprometida en un contrato de compra-venta de un hijo con la pareja Stern, se negó a cederlo. La madre subrogada fue doblemente desacreditada como legítima madre en base a sucesivos juicios descalificativos entorno a su racionalidad (Pitch, 2003, p.48). En primer lugar, el juez la acusó de ser «fría, testaruda y calculadora» por su participación en un contrato de estas características. No obstante, la negativa final fue justificada en base a su carácter «irracional y emotivo». La madre contratante no era estéril, razón por la cual - de acuerdo con Pitch (2003) - el juez no la consideró «lo bastante femenina», así que el único candidato racional y competente para la atribución de la paternidad y el establecimiento de contratos fue el señor Stern, padre genético del niño.

La regulación tecno-científica de los procedimientos médicos asociados a la MS ha sido codificada mediante el lenguaje político del patriarcado. La antropología machista del individuo propietario es aplicada en términos de 
sanidad, funcionalidad y riesgo al cuerpo femenino: «la mujer de sitúa como su propiedad exactamente en la misma relación externa en que un hombre se encuentra con su fuerza de trabajo o con su esperma; no hay nada distintivo en la condición de mujer» ${ }^{15}$ (Pateman, El contrato sexual, citado en Pitch, 2003, p.46).

Esta operación es registrada por el Derecho con la finalidad de garantizar el cumplimiento de los contratos de subrogación por lo que respecta a la paternidad genética. La legislación y la jurisprudencia tienden a fijar el criterio de atribución de la potestad sobre su hijo en la paternidad biológica-genética y en la adecuación matrimonial de la pareja. En gran parte de la casuística la madre subrogada solo cuenta como «trabajadora de gestación» ajena, mientras que la madre social o por elección participa desde la posición de mujer del hombre contratante. El reconocimiento jurídico de la maternidad deviene muy complejo o a-legal cuando falta la presencia de una figura paternal, masculina y heterosexual vinculada genéticamente a la descendencia.

Pateman cuestiona que la subrogación sea un neutral patrón de intercambio de servicios entre mujeres. Ante esta definición propone la tesis que dicha práctica consiste más bien en el trabajo femenino de gestación del esperma de un hombre a cambio de dinero (Pitch, 2003, p.44). Mediante el cuestionamiento de la neutralidad moral de la MS pretende remarcar que las relaciones contractuales tienen lugar en un campo social marcado por la estructura institucional y ética del patriarcado.

Perfilando esta perspectiva Pitch (2003) afirma que el feminismo contractualista sostiene una concepción de la subjetividad que impide el reconocimiento de la diferencia y las desiguales condiciones sociales femeninas. Sin embargo, la relevancia de su punto de vista no consiste en la frecuentemente criticada abstracción del sujeto de derechos, sino en la identificación de una figura masculina en la matriz del sujeto liberal ${ }^{16}$.

La corporeidad femenina no puede ser ajena a los atributos del sujeto político o de derechos, razón por la cual, como apunta Pitch, la constitución de un «sujeto sexuado, capaz de expresar en primer lugar la diferencia femenina y masculina» (2003, p.42-43) es el requisito fundacional de toda legislación feminista que pretenda garantizar la autonomía de la mujer. Más allá de la crítica de Iacub $^{17}$ y Shalev a la «mística del útero y la maternidad» (Pitch, 2003, p.46), la subjetividad no se reduce a la etérea capacidad de 


\section{Francesch Sabaté-Maternidades Confrontadas}

elección racional. Al contrario, se desarrolla sobre el cuerpo y el sexo particulares en el contexto de las relaciones sociales con los demás.

Las resoluciones judiciales fundamentadas en la patriarcal pretensión «de irracionalidad del sujeto femenino» en base a criterios biológicos embarazo, menstruación, etc. - del cuerpo de la mujer, pueden ser afrontadas mediante una política feminista basada en el cuerpo. La sexuación del sujeto político manifiesta la desigualdad y la injusticia a partir del reconocimiento del valor de la implicación de los cuerpos en el desarrollo de la actividad reproductiva.

Las pensadoras ecofeministas y las voces feministas críticas con el neocontractualismo coinciden en la defensa de la primacía de la autonomía sobre el propio cuerpo como innegociable punto de partida en el proceso de emancipación de la mujer. La aceptación de la prioridad del contrato en tanto que mecanismo liberador conlleva inevitablemente el apelo a la injerencia del Estado para garantir su cumplimiento. Esta problemática postura desemboca en la intensificación del histórico control del cuerpo femenino por parte de las instituciones burocráticas, científicas y de clase, todas ellas vinculadas al patriarcado ${ }^{18}$.

Consecuentemente una orientación emancipadora de las prácticas de MS debería apoyar la tutela de las mujeres sobre el hijo resultante de una relación sin ánimo de lucro entre la madre genética y la madre gestante.

\section{La jerga de los nuevos derechos y su mercadeo}

A menudo la defensa de la inclusión de la maternidad subrogada dentro del catálogo de prestaciones de provisión pública garantizada se deriva de una particular definición médica. Se concibe sesgadamente la MS como una técnica orientada a la "cura" de una esterilidad de realzada connotación socialmente patológica. Pretendidamente en pro de la igualdad sexual este debate tiende a esquivar la distinción entre la esterilidad causada por disfunciones en el aparato reproductor femenino y la incapacidad de procrear de una pareja gay, situada más allá de la salud de sus órganos sexuales.

Esta indistinción implica la extirpación del núcleo político de la igualdad históricamente perseguida por la izquierda. La reivindicación de la igualdad material no ambiciona abolir las diferencias biológicas entre individuos; de ellas hace abstracción con tal de aplicar la igualdad política a 
la percepción de la redistribución y las discriminaciones positivas correspondientes al desarrollo de los derechos sociales, económicos y políticos.

La pretensión de implementar políticas redistributivas en materia de igualdad de capacidades biológicas o genéticas implica la confusión de los objetos de justicia -en este caso las diferencias biológicas y las desigualdades sociales - con los sujetos por los cuales se hace justicia, es decir, las mismas personas portadoras del material genético diferenciado. La equiparación de las posibilidades reproductivas no equivale a una redistribución de bienes apropiables repartidos de forma desigual. Las cualidades que constituyen el sexo de cada persona son características de valor inconmensurable.

De todos modos, es necesario dar respuesta a la presente injusticia en el acceso a la MS. La posibilidad de establecer una relación de subrogación depende básicamente del poder adquisitivo necesario para contratar este servicio en el exterior. La existencia de un puente mercantil que esquiva la legalidad supone la institucionalización de una desigualdad de derechos respaldada por el poder supraestatal de agentes económicos con capacidad para operar en mercados transnacionales.

La escasez de trasplantes de órganos no pone en duda el carácter intolerable de su distribución mercantilizada en función del poder adquisitivo del enfermo. Del mismo modo, la indisponibilidad o el complejo acceso a las mujeres dispuestas a gestar el hijo de otro no justifica la conversión de la maternidad en un "servicio" mercantilizado o apropiable. Al igual que con la gestión de las listas de espera por trasplantes, el Estado debe intervenir para paliar posibles agravios de justicia distributiva, así como para evitar la proliferación de mercados negros de órganos humanos que empujen a las personas necesitadas a la venta de sus recursos corpóreos. Una posible línea regulativa puede extraer del ejemplo planteado algunos principios orientativos.

Sin precisar la invención de un nuevo derecho, el Estado ha de reconocer la existencia de deberes colectivos entorno a la maternidad subrogada así como su pertenencia al campo social de la reciprocidad. La administración pública podría organizar o supervisar listas de mujeres donantes dispuestas a gestar los hijos de las personas incapacitadas solicitantes. Este modelo podría ser incluido en de las prestaciones de la 
sanidad pública universal sin provocar la expansión del mercado de la vida humana que se derivaría de la creación de un nuevo "derecho a la maternidad subrogada".

Las medidas propuestas no parecen propensas a dejar un rastro de litigios jurídicos entorno a la filiación de los hijos. La participación en la relación de donación no requeriría el recurso a relaciones contractuales privadas, incapaces de trazar fronteras nítidas entre la venta del uso del útero, la venta de la tutela, la cesión voluntaria de un servicio a cambio de cierta manutención, una renuncia revocable a un hijo, etc. Por otro lado, dicho modelo podría basarse en una lista más o menos estandarizada de derechos y deberes de la parte solicitante y la parte donante. Su tipificación clarificaría la prioridad de la madre gestante por lo que respecta a su autonomía y al carácter indisponible de su cuerpo, así como la justa medida del peso jurídico de la «voluntad procreacional».

\section{Conclusiones}

El análisis de la maternidad subrogada y el desarrollo de soluciones regulativas requiere la construcción de fundamentos terminológicos sobre los cuales instalar las críticas a las injusticias que circundan tanto la permisión como la censura de esta práctica.

En este artículo he tratado de desgranar temáticamente el desconcierto que dificulta la percepción de los problemas derivados de la socialización de la MS, así como los factores que limitan su potencial emancipador.

La dicotomía natura-cultura interviene como un dispositivo patriarcal en los litigios jurídicos entorno a la MS. Ésta opera como un argumento pseudocientífico en el momento de discernir si la voluntad de la madre subrogada es en todo momento libre o por otro lado, deviene obstaculizada por los cambios hormonales asociados al embarazo y la biología femenina en general.

El lenguaje profesionalizador que viste los discursos favorables a la MS con ánimo de lucro enmascara la venta de la potestad sobre la descendencia. No se trata de la mera remuneración de un embarazo o "servicio de gestación", pues el contrato finaliza con la entrega del hijo y la potestad sobre éste. A la par, mediante de la jerga liberal de la separación entre el cuerpo y la persona se trata de justificar el carácter físicamente y psíquicamente inofensivo de la técnica para la madre subrogada. 
El contrato de subrogación ha sido presentado como el canal jurídicopolítico de garantía de los derechos y de la libertad económica de la madre subrogada y la parte solicitante. Lejos de la neutralidad y la protección, la contractualización de las relaciones reproductivas sujeta la mujer gestante a los compromisos establecidos por lo que respecta al uso de su cuerpo y la dación del hijo y de la potestad sobre éste. Determinado por la carga patriarcal presente en la legislación que regula las relaciones familiares en muchos países, el contrato de MS fortalece el poder de la presencia masculina en los litigios por la tutela del hijo y fuerza las partes a pensar su relación en términos laborales.

El pensamiento neoliberal celebra el dominio de la genética como un triunfo de la voluntad sobre la arbitrariedad biológica y la necesidad de gestar. Contrariamente la genética deviene de forma progresiva un nuevo criterio preponderante en el reconocimiento de la potestad sobre la descendencia. Su carácter mesurable y certificable la convierte en un elemento normativo adaptable a la lógica jurídica y al contrato de subrogación. En lugar de situar a la mujer más allá del condicionamiento biológico la genética subyuga la madre gestante a éste en la medida en que los genes coinciden con la voluntad procreacional del progenitor intencional. Dicha voluntad no debe ser confundida con la emancipación femenina, pues consiste en deseos individuales de instrumentalización y poder proyectados sobre el cuerpo de otras mujeres.

El lenguaje de la reciprocidad y el don resulta más apropiado para una regulación de la MS. La reproducción y la familia pertenecen al campo social de las relaciones recíprocas y no remuneradas. La intromisión de nociones económicas como la remuneración, el contrato de trabajo y el derecho laboral - sean consideradas equitativas o no- implica la mercantilización de la procreación. La promoción o la simple permisión de un sistema de donantes de capacidad reproductiva y potestad sobre la descendencia es la intervención estatal más proporcionada, no requiriendo la creación de nuevos derechos asociados a la reproducción humana.

\section{Notas}

${ }^{1}$ «Conjunto de rasgos y modos de comportamiento que conforman el carácter o la identidad de una persona o comunidad». Real Academia Española. Diccionario de la Lengua. Edición del Tricentenario [en línea]. 


\section{Francesch Sabaté-Maternidades Confrontadas}

2 Es el grupo de mayor antigüedad políticamente organizado entorno a la lucha por el reconocimiento de la maternidad y la paternidad de los progenitores españoles de hijos nacidos por MS en países donde ésta ha sido legalizada, o al menos se practica bajo cierta regulación. SNH hace campaña desde el año 2008 por la regulación de la MS en tanto que «derecho reproductivo» de aquellas familias - gais incluidas - que no puedan gestar sus hijos.

3 Atado a la especialización femenina en la producción y la custodia de la solidaridad, históricamente el don ha regido las relaciones vinculadas a la reproducción humana.

${ }^{4}$ Iacub (2005) fundamenta su defensa de la subrogación mercantil en el modelo legislativo desarrollado en California.

5 «Per la prima volta. senza dubbio. nella storia occidentale. la maternità diventava senza alcuna "frode" tanto poco carnale quanto poteva esserlo la paternità». (Iacub, 2005, p. 156).

6 La relación sexo-reproducción no puede ser eludida por lo que respecta a sus connotaciones en sociedades que la conciben indisociable. En países como la India la subrogación se encuentra estigmatizada por analogía con el trabajo sexual, hecho que contribuye a la estratificación social de esta actividad. M. I. Jociles (Ed.) Revelaciones, filiaciones y biotecnologías, p. 317-346.

${ }^{7}$ En el informe Maternidad subrogada: Explotación de Mujeres con Fines Reproductivos (EMFR) Tailandia, la India, Nigeria y México son algunos de los países estudiados por la Comisión Especial de Lucha Contra la Trata de Personas de la Cámara de Diputados mexicana por su vinculación con el comercio de mujeres y menores mediante el establecimiento de contratos ilícitos de MS.

${ }^{8}$ Comentario de «Pelayo», en respuesta al artículo de Salazar, O. (2016). Una mirada feminista sobre la gestación por sustitución. Hombres Igualitarios. Revista digital de AHIGE. 94, 1 octubre 2016.

${ }^{9}$ Pelayo, Ibídem.

${ }^{10}$ Para un análisis documentado de la distribución del peso del trabajo reproductivo ver: Giménez, A. Reconocer diferencias atribuyendo derechos: los problemas regulatorios del género. J. A. Estévez Araújo, (Ed.), (2013). El libro de los deberes. (p. 115-137). Pese a que algunos estudios han constatado el hecho que muchos padres en situación de desempleo de larga duración han asumido un rol más activo y paritario en las tareas de cuidado de su prole, Connell ha destacado que en términos relativos las encuestas muestran que el incremento del tiempo dedicado a la familia como consecuencia de la desocupación, ha sido muy menor entre los hombres que entre las mujeres (2011, p.49-50).

11 El diagnóstico genético preimplantacional consiste en la práctica de un test genético previo a la implantación de los embriones mediante inseminación artificial. Su fin puede ser la detección de trastornos hereditarios en un embrión obtenido mediante fecundación in vitro. Esta técnica garantiza una descendencia exenta de enfermedades genéticas transmisibles por los progenitores con una probabilidad próxima al $100 \%$.

12 «La diferencia entre hijos «adoptivos» y «biológicos» no tenía significado alguno para los redactores del Código Civil [napoleónico], porque en realidad ningún hijo era biológico en el sentido en que hoy lo entenderíamos» (Iacub, 2005, p.24-25).

${ }^{13}$ En su defensa de los contratos comerciales de subrogación Iacub (2005) no tiene en cuenta la relevancia normativa y política de terceros actores como las corporaciones tecnocientíficas. Éstas han desarrollado los servicios técnicos que hacen posible la subrogación y la disociación de la maternidad. La verdad del parto en tanto que hecho biológico encaja dentro del modelo de inspiración científica del Derecho moderno. De acuerdo con Esteve Pardo, la fundamentación del Derecho en «certezas comprobables» por 
analogía con las disciplinas científicas es un modo de creación de la normativa jurídica que - vista la rapidez de los cambios en lo veraz y lo posible en el saber y la técnicaactualmente puede llegar a desbordar los agentes legisladores. Dicha situación propicia el proceso de producción y supervisión de la normativa que regula el uso de la técnica. La regulación es elaborada y supervisada por las mismas empresas tecnocientíficas que a ella se encuentran sujetas. (Esteve Pardo, 2009, p.60-62).

14 «En la base de las tesis de Shalev está, como se ha dicho, el presupuesto de que lo que cuenta, a los fines de la validez del contrato, son las intenciones expresadas en el momento de su estipulación» (Pitch, 2003, p.49).

${ }^{15}$ En este sentido la contractualización del cuerpo femenino en términos de «propiedad» y «garantía de la autonomía y la elección individual» empujan hacia una creciente apelación al control estatal, el cual como hemos observado, ha sido delegado en la burocracia privada de las corporaciones tecnocientíficas. Este control puede incidir en detrimento de la voluntad y el criterio de la madre gestante. Mies ha denunciado que «un número creciente de profesionales de la ingeniería genética están empezando a describir el útero femenino como un "entorno peligroso" para el feto». Consecuentemente, proliferan las leyes que penan la «negligencia materna» o «el incumplimiento premeditado de las instrucciones médicas». Inclusive en algunos países como Inglaterra la autorización de la procreación en las parejas estériles es dejada en manos de los médicos, invistiendo poderes discrecionales e intrusivos sobre las vidas particulares a individuos susceptibles de guiarse por criterios tecnocráticos o subjetivos que nada tienen que ver con la emancipación sexual y la tutela de los derechos (Mies \& Shiva, 1998, p. 59).

${ }^{16}$ El sujeto del contrato se constituye como propietario de sus propias capacidades y atributos, como propietario de la propia persona, en tanto, separado y separable de la misma. Pero este sujeto, el individuo propietario, igual por este hecho al resto, no es, como muchos críticos sostienen, según Pateman, meramente inmaterial (abstracto, neutro). Al contrario, es una construcción a partir de un cuerpo que es masculino, «un ser del otro sexo solo puede ser una modificación del individuo, nunca un ser diferente pues su unidad resultaría puesta en peligro». Pateman, El contrato sexual, citado en: (Pitch, 2003, p.42-43).

${ }^{17}$ Iacub tacha de irracionales las voces defensoras de «la saggezza del corpo» (2005, p.193).

${ }^{18}$ Podríamos resumir las fuerzas aquí descritas en el control biopolítico, no obstante, merece la pena desgranar algunos de los factores con tal de apreciar su heterogeneidad y las múltiples dimensiones. 


\section{Referencias}

Badinter, E. (2011). La mujer y la madre. Un libro polémico sobre la maternidad como nueva forma de esclavitud. Madrid: La esfera de los libros.

Bartolini, M., Pérez, C. \& Rodríguez, A. (2014). Maternidad subrogada: Explotación de Mujeres con Fines Reproductivos (EMFR). México, D.F.: Capricho Ediciones.

Mc Lachlan, H. V.; Swales, J. K. (2009). Commercial Surrogate Motherhood and the Alleged Commodification of Children: A Defense of Legally Enforceable Contracts. Law and Contemporary Problems, 72, 91-108.

Connell, R. (2011). Confronting Equality. Gender, Knowledge and Global Change. Cambridge: Polity Press.

Esteve Pardo, J. (2009). El desconcierto del Leviatán. Barcelona: Marcial Pons.

Estévez Araújo, J. A. (Ed.),(2013). El libro de los deberes. Las debilidades e insuficiencias de la estrategia de los derechos. Madrid: Editorial Trotta. Fuentes, P. (2016). ¿Qué es la Subrogación Gestacional? Madrid: Son Nuestros Hijos. Asociación de Familias por Gestación Subrogada. Recuperado de http://sonnuestroshijos.blogspot.com.es/p/qu.html. Iacub, M. (2005). L'Impero del ventre. Per un 'altra storia della maternità. Verona: Ombre Corte.

Jociles, M. I. (Ed.), (2016). Revelaciones, filiaciones y biotecnologías. Una etnografía sobre la comunicación de los orígenes a los hijos e hijas concebidos mediante donación reproductiva. Barcelona: Edicions Bellaterra.

Mies, M. \& Shiva, V. (1998). La praxis del ecofeminismo. Biotecnología, consumo y reproducción. Barcelona: Icaria editorial.

Mies, M. (1998). Patriarchy and Accumulation on a World Scale: Women in the International Division of Labour. Trowbridge: Redwood Books.

Pitch, T. (2003). Un derecho para dos. La construcción jurídica de género, sexo y sexualidad. Madrid: Editorial Trotta.

Real Academia Española. Diccionario de la Lengua. Edición del Tricentenario. Madrid: Real Academia Española. Recuperado de http://dle.rae.es/?id=H3xAc5s 
GÉNEROS-Multidisciplinary Journal of Gender Studies, 6(2) 1384

Salazar, O. (2016). Una mirada feminista sobre la gestación por sustitución.

Hombres Igualitarios. Revista digital de AHIGE. 94, 1 octubre 2016.

\section{Pau Francesch Sabaté}

\section{Contact address:}

Facultat de Filosofia.

Universitat de Barcelona

Carrer Montalegre 6-8, 08001 Barcelona.

E-mail address: paucatgn@gmail.com 